\title{
Community structure and trophic level interactions in the terrestrial ecosystems: a review
}

\begin{abstract}
Community is one of the hierarchies of ecological organizations containing different species of organisms interacting in space and time. The structural components of the biotic communities are mainly composed of plants, animals, and microbes. This paper aims to review and discuss how community structures are organized and trophic level interactions function and shape the biological communities in the terrestrial ecosystems. For example, the paper reviewed and discussed community structure and trophic level interactions in the tropical rain forest, grassland, and desert ecosystems. The paper also examined how trophic cascades control the different populations in the terrestrial communities. The terrestrial biotic communities are functionally diversified and complex because the number of trophic levels increases with the increase in productivity gradients. Different factors may interact together and synergistically affect the biotic communities in the terrestrial ecosystems. For example, primary productivity of a system is markedly affected by precipitation, incident light, temperature, disturbance, nutrients, and resistance to herbivory and cascading food web effects. Thus, holistic approach should be sought for any conceptual models to explain patterns of productivity and biomass distribution in the terrestrial communities. This in turn would help to effectively simulate the community structure, trophic level interactions, and control of the terrestrial biotic communities with reference to specific spatial and temporal scale. Moreover, the role of behavior and life history traits, prey defenses versus prey tolerance, vertical and horizontal interactions are important factors which could affect the structure, complexity, and diversity of food webs in the terrestrial biotic communities. In conclusion, this review paper suggested that the different hypotheses developed by various scholars of the community ecology have to be considered in an integrated fashion in order to clearly understand and explain the plausible mechanisms that influence the community structure and trophic level interactions in the terrestrial ecosystems.
\end{abstract}

Keywords: biomass distribution, cascades, community ecology, ecological organizations, functionally diversified, holistic approach, primary productivity, productivity gradients, structural components, terrestrial communities
Volume 2 Issue 6 - 2017

Solomon Ayele Tadesse
Debre Berhan University, Ethiopia

Correspondence: Solomon Ayele Tadesse, Department of Natural Resources Management, College of Agriculture and Natural Resource Sciences, Debre Berhan University, PO Box 445, Debre Berhan, Ethiopia, Tel +25I - III-68I5440, +25I-946703660, Fax +25I-III-68I2065, Email solomon.ayele1972@gmail.com

Received: December 09, 2017 | Published: December 29, 2017
Abbreviations: EEH, ecosystem exploitation hypothesis; ELH, energy limitation hypothesis; GWH, green world hypothesis; HSS, hairston smith and slobodking

\section{Introduction}

Organisms have their own patterns of distribution and biological organizations functioning in the natural system. Community is one of the hierarchies of ecological organizations composed of different species of organisms interacting in space and time. Photosynthesis is the fundamental biological process by which radiant energy is converted to chemical energy and thereby readily becomes available for all living things existing on the planet earth. ${ }^{1}$ Consequently, the type and extent of primary productivity determines the distribution, abundance, and diversity of consumers that live being subordinate to the photosynthetic products of green plants especially in the terrestrial ecosystems. There are several factors which could determine the net annual primary productivity and plant biomass production as well as its distribution among producers and various trophic groups of consumers. The major factors may include water and nutrient availability, climate, plant defenses, environmental heterogeneity, disturbance, stochiometry, and consumption by herbivores. ${ }^{2,3}$ The interactions of plants and animals go back to evolutionary times. ${ }^{4}$
Various components of the terrestrial ecosystems naturally work towards regulating and controlling the primary productivity and distribution of biomass among plants and animals across the various trophic levels of the biological community. Understanding how the biological communities in the terrestrial ecosystems function in the presence of different structural components is the central point of plant-animal interactions both from ecological and evolutionary contexts. However, various classical approaches dealing with biological communities have still incomplete information to give straightforward evidences regarding the complex ecological and evolutionary processes and the controlling mechanisms in the terrestrial ecosystems. ${ }^{3}$ This is because, compared with the aquatic ecosystems, the dynamics, complexity, and diversity of the terrestrial communities are too tremendous to precisely enumerate and quantify. For example, the GWH proposed that some parts of the world have remained green primarily because herbivores are held in check by their enemies and also don't consume a large fraction of indigestible plant biomass, ${ }^{5}$ see also Figure 1. However, the Fretwell-Oksanen EEH noted that varying productivity, herbivory, and predation make habitats green in systems with one or three trophic levels, but barren in systems with two or four levels; ${ }^{6}$ see also Figure 2. The FretwellOksanen EEH model also predicts that top-down control should be in one trophic level but bottom- up control in three trophic levels. 
Oksanen $^{7}$ generally suggested that the number of trophic levels, and top-down or bottom-up control is a function of the magnitude of productivity of the terrestrial ecosystem.

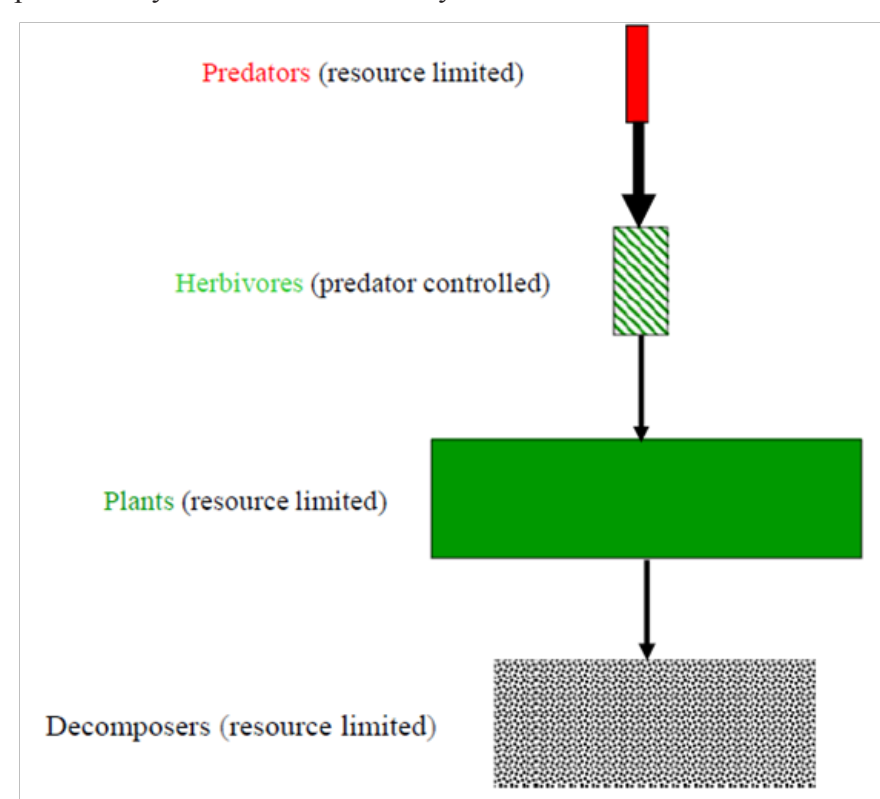

Figure I Hairston et al. ${ }^{5}$ (HSS) the trophic control hypothesis (usually referred to as 'the green world hypothesis').

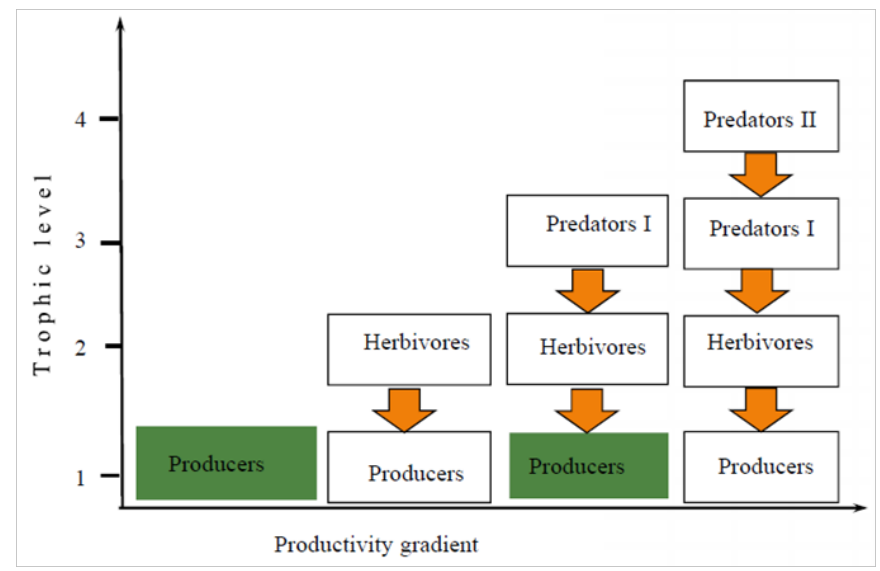

Figure 2 Fretwell-Oksanen Exploitation Ecosystem Hypothesis (EEH) as a function of productivity gradient model. The model suggested that varying productivity, herbivory, and predation make habitats green in systems with one or three trophic levels, but barren in systems with two or four levels adapted from. ${ }^{6}$

Menge \& Sutherland ${ }^{8}$ model predicts that physical disturbance, predation, and competition are the three major ecological processes which mainly determine the community structure and biological organizations in the terrestrial ecosystem. In stressful environments, the model predicts herbivores have little effect because they are rare, and plants are directly regulated by the environment. However, in moderately stressful environments, the model further predicts consumers are ineffective at controlling plants, and plants attain high densities where competition among them is the dominant interaction and controlling mechanism. In benign environments, Menge and Sutherland ${ }^{8}$ model predicts that consumers control plant biomass, hence plant competition is low. Predation is also the dominant biological interaction under these benign conditions. Both $\mathrm{HSS}^{5}$ and Menge and Sutherland ${ }^{8}$ models predict that predator removal will strongly affect herbivore numbers. However, the Hairston et al. ${ }^{5}$ model predicts that removal of herbivores, in benign environments, will not change the plants (which are not limited by them). The Menge and Sutherland ${ }^{8}$ model predicts that the herbivores have an important influence on plant abundance. The HSS $^{5}$ model predicts intense competition between plants while that of Menge and Sutherland ${ }^{8}$ model does not.

A clear example of the far-reaching impacts of predators on ecosystem processes and biodiversity comes from Yellowstone National Park. When wolves Canis lupus were eliminated in 1926, elk Cervus elaphus shifted habitat use and fed extensively throughout the different habitats in the park. ${ }^{9-11}$ This resulted in a reduction in the abundance and distribution of aspen Populus tremuloides, cottonwoods Populus deltoides and willows Salix spp. When wolves were reintroduced in 1995, elk responded by avoiding or feeding less extensively in areas with poor visibility or few escape routes. ${ }^{9-11}$ Within a few years, woodlands started re-establishing in these areas. In contrast, elk continued to keep trees below $1 \mathrm{~m}$ in height in the safer more open areas of the park. This suggested that the reintroduction of the wolves has not only benefited the trees, but also cascaded to bird species and beavers Castor canadensis that required extensive woodlands. Furthermore, beavers are now building dams in these areas and restoring wetlands to the park. ${ }^{11}$ This paper aims to review and discuss how community structures are organized and trophic level interactions function and shape the biological communities in the terrestrial ecosystems.

\section{The structure of the terrestrial communities}

The structural components of the biotic communities in the terrestrial ecosystems are mainly composed of plants, animals, and microbes. However, the terrestrial communities are functionally more diversified and complex than the aquatic ecosystems. ${ }^{12}$ They mainly consist of producers, consumers, and detritivores of numerous species which interact and inter-depend one on another for co-existence and thereby shaping the structure and the transfer of matter and energy along and across the various trophic levels. For example, green plants are producers as they are the ultimate converters of the radiant energy into chemical energy through the process known as photosynthesis. However, herbivores depend on green plants for their chemical energy to maintain their survival and reproductive fitness. Carnivores are the other functional components of the biotic communities that obtain digestible foods by preying on herbivores. Moreover, detritivores are the other tropic components of the terrestrial ecosystems that derive their chemical energy by exploiting the dead parts of plants and animals. $^{13}$

The dynamics, diversity, and complexity of the structure of the biotic communities in the terrestrial ecosystems depend on the productivity gradient of the habitats. ${ }^{12,13}$ For example, compared to the hot desert ecosystem where water is a limiting factor, it is more likely to observe complex structural and functional diversity and abundance of the biotic communities in the tropical rain forest ecosystem where the soil is productive and water is available see also Figure 3. As a result, it is common to see longer and more complex food webs in the productive habitats of the tropical rain forest ecosystem as compared to the less productive habitats in the desert environments. ${ }^{6,8,14,15}$ Irrespective of the natural productivity of the system, anthropogenic and other natural catastrophic factors may also play a crucial role to affect the diversity and complexity of the terrestrial ecosystems. For example, man has been over exploiting the tropical rain forests since the time of civilization. As a result, the structural and functional 
diversity and complexity of the biotic communities in the tropical rain forest ecosystem have been rapidly changing compared to that of the less productive desert ecosystem. ${ }^{7,13,16}$

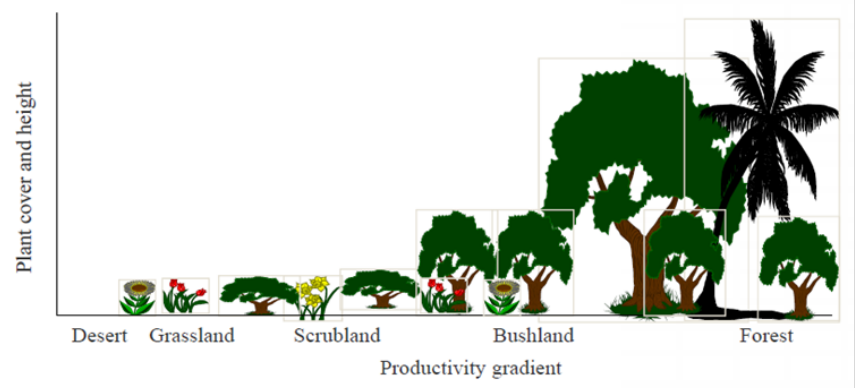

Figure 3 Changes in community structure along productivity gradient in terrestrial communities.

The terrestrial communities are usually in a steady state of change due to the effects of internal ecosystem engineers and external biotic and abiotic environmental factors. ${ }^{11}$ Among the internal ecosystem engineers, the devastation of the savannah woodland by elephants is a good example in affecting the composition and the structure of the plant communities in the terrestrial ecosystems. Moreover, the impacts of man and fire could be the best known external factors which affect the structural and functional diversity, complexity, and abundance of the biotic communities in terrestrial ecosystems. ${ }^{11,12}$ Compared to aquatic communities, it is hard to define the terrestrial communities because they lack definite boundary of size and structure. However, they are rich in species with a wide range of size at all trophic positions including producers, herbivores, and predators. ${ }^{12,13}$ Consequently, they are potential for high inter-trophic level interactions with many changes in community qualities along productivity gradient, such as plant physiognomy and its effect on the type of herbivores that dominate the community, plant quality, and major herbivore size. ${ }^{17,18}$ Thus, in order to recognize the complexity of the terrestrial communities, we have to make more realistic abstraction-not trophic levels, but sub-groups or guild species as well as the importance of horizontal interactions. ${ }^{13,17}$ Even though there is a lack of communitylevel size structure, recognize that still food-chains are size structured see also Figure 4.

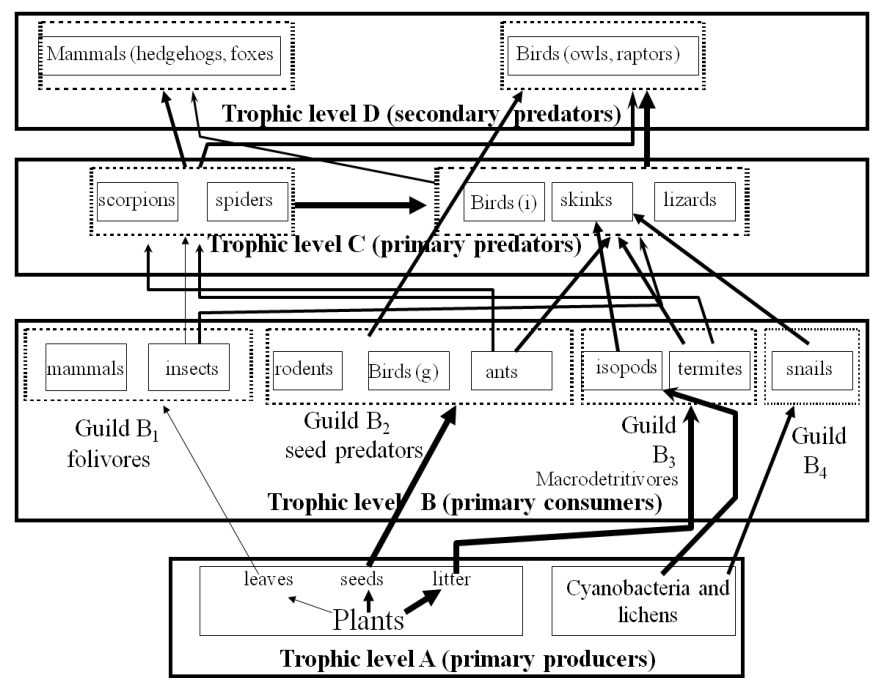

Figure 4 An example of community structure and various trophic leve interactions among the biotic communities in the desert ecosystem. Species within a guild are expected to compete on resources, whereas species within a trophic group are expected to suffer from apparent competition. ${ }^{27}$

\section{Trophic level interactions in the terrestrial communities}

Species in biotic communities interact in various ways. Plantanimal interactions could be good indicators of these phenomena. The main type of such interactions is to acquire sufficient energy that maximizes individual's survival and reproductive fitness. ${ }^{13,16}$ Previous studies noted that competition among different guild species in biotic communities could be one of the potent natural forces which affect the niche breadth and overlap among competing species for similar habitat resources. ${ }^{19-22}$ For example, theory suggests that higher diversity should shrink niches, allowing coexistence of more species locally. ${ }^{21,23}$ Empirical studies suggested that predator-prey interaction is the other type of functional diversity that shapes species composition and dynamics of terrestrial communities..$^{13,14,17,24}$ However, for better understanding, it is crucial to discuss each trophic level as follows.

\section{The primary producers' trophic level}

This mainly includes green plants which are responsible to convert the radiant energy into a useable chemical energy. Accordingly, producers make chemical energy readily available for themselves as well as to other trophic levels (i.e., consumers and detritivores). In the terrestrial communities, the primary producers are not only photosynthetic green plants, but also cyanobacteria and lichens ${ }^{13,17}$ see also Figure 4. Primary productivity on land is a function of temperature and also tightly correlated with precipitation. Moreover, the distribution, abundance, and diversity of green plant communities on the surface of the planet is mainly governed by location, amount of solar radiation reaching the earth's surface, local and regional topography, and type of soils. .,3,12 $^{2}$

\section{The consumers' trophic levels}

Depending on their foraging nature, these trophic levels include herbivores, predators, parasites, and parasitoids that ecologically interact in various ways. ${ }^{2,3,12,13}$ Consumers form aggregated trophic levels that are posited to regulate the biomass of trophic level on which they feed. For example, predator-prey interaction is one of the most pervasive forces which determine species composition, abundances, distributions, and behavior of organisms in the terrestrial biological communities. ${ }^{23-26}$ Thus, the consumers' trophic level could be briefly discussed as follows.

\section{Herbivores (primary consumers)}

Herbivory is believed to have first evolved in the terrestrial mammals during the late cretaceous period some 100 million years ago. ${ }^{4}$ Some evidences supported that herbivores have exerted various impacts on the terrestrial plant communities since ecological and evolutionary times. ${ }^{5,18}$ Thus, plants and animals have evolved to have structural and functional interactions and inter-dependencies which could influence the dynamic characteristics of the terrestrial ecosystems and the structures of the biotic communities. ${ }^{1,13,17,27}$ In these interactions, plants provide energy and nutrients to upper trophic levels through herbivores. Plants in turn have developed several defensive strategies and mechanisms against herbivorous organisms. ${ }^{27}$ In fact, the level of plants' potential to defend against herbivory attack varies from plants to plants; and also influenced by the availability of resources in the environment. ${ }^{1}$ However, defenses are not universal which means that all plant species are still vulnerable at least to some specialists. ${ }^{3}$ Thus, defenses only restrict herbivore effectiveness by decreasing rates of discovery, consumption or digestion. The generality suggested that more defended plant species 
increase with the increasing productivity. ${ }^{1,27}$ Hence, compared to the less productive ecosystems, most plant biomass is well defended in productive ecosystems.

According to those ecologists who deal with plant-animal interactions, herbivores are found to have closest direct dependence and interactions with green plants. ${ }^{16}$ However, macro-herbivores are negligible players in the terrestrial systems (e.g. forest ecosystem) where most plant productivity directly goes to detritivores. ${ }^{1,13,17,27}$ This means that most of the plant biomass is not eaten by herbivores in terrestrial forest ecosystem because all that is green is not edible rather cruddy (i.e. lower nitrogen and protein content) for herbivores. ${ }^{6}$ On top of this, plants have rough leaves because they are not only lignified and fibrous, but also rich in cellulose and carbohydrate. ${ }^{12}$ Furthermore, plants contain toxins, repellents, growth inhibitors, and digestibility reducing compounds that can be present all the times which constitute secondary metabolites..$^{25,26}$ Previous studies showed that tannins act as toxins or as digestibility reducers. For example, tannins may reduce food digestibility by interfering with bacterial fermentation processe ${ }^{28}$ or by impairing the use of absorbed nutrients. ${ }^{25}$ Thus, on average, herbivores consume about $5-10 \%$ of the net annual primary biomass production of plants in the terrestrial ecosystems ${ }^{3,22,29}$ especially in the forest ecosystem. However, herbivores like insects that have high reproductive potential and periodically reach high densities which in turn bring irrefutable economic damages through massive defoliation and growth reductions mainly in mono-crops though it is a rare phenomenon in natural systems. ${ }^{26}$ In spite of their negative impacts on plants, herbivores have tremendous contributions to the terrestrial communities. For example, herbivores play a crucial role in facilitating pollination, seed dispersal and seedbed preparation, adding organic manures and also reducing competition among plants through their selective foraging behavior on certain types of plant species.

\section{Predation, parasitism, parasitoids, and pathogens}

Ecologists have long recognized the importance of predators in structuring and shaping the terrestrial ecosystems. For example, environments with and without large predators have been used to assess the direct impacts of predation and/or the loss of such processes. ${ }^{9-11,30}$ Polis $^{12}$ noted that all of the four Ps (i.e., predation, parasitism, parasitoids, and pathogens) work in one way or the other way round to depress the number of herbivores so that they enhance plant productivity and biomass distribution in the terrestrial ecosystems. However, pathogens/parasites occasionally suppress herbivores and allow greater plant biomass. ${ }^{26}$ Some theoretical models suggested that both resources and predators interact to structure natural food webs in the terrestrial ecosystems. ${ }^{5,6,12,17}$ Consequently, the magnitude of those interactions is variable both in space and time. A variety of theoretical models are available to predict such variations; however, they vary in the assumptions that they made and in their predictions as well. ${ }^{5,17,27}$ Moreover, the degree of prey vulnerability to predators may affect the effects of predators on biomass of the terrestrial ecosystems along productivity gradients. ${ }^{12}$

\section{The detritivores trophic level}

This trophic level mainly comprises of organisms which derive their chemical energy by feeding on the dead bodies of plants and animals. Uneaten plants enter the detritus food web where they are processed by microbes and metazoan ${ }^{6,13,17,25}$ see also Figure 4. In forests, most of the primary production (about 90-95\%) ${ }^{29}$ goes to the decomposers because there is very low consumption efficiency by herbivores ${ }^{6,12}$ Figure 5. Thus, detritivores play decisive positive role in facilitating the recycling of nutrients by decomposing the dead organic matters. Detritivores can also reduce the occurrence of natural fire hazards in the terrestrial ecosystems by removing the accumulated downed woody debris of plant communities. ${ }^{17,25}$

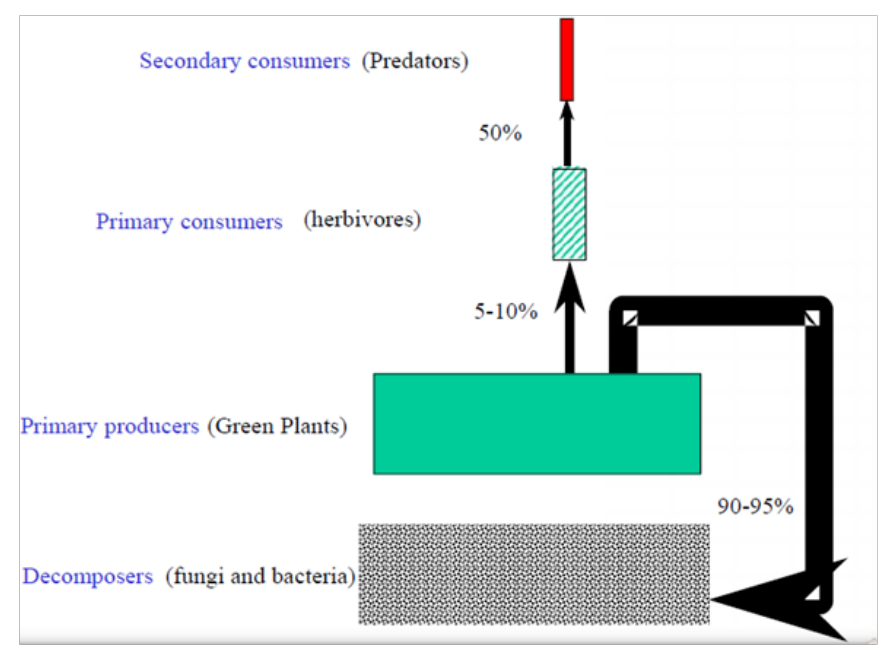

Figure 5 The energetic transfer efficiencies along the different tropic levels in the terrestrial communities adapted from. ${ }^{29}$

\section{Trophic cascades and population control in terrestrial communities}

Solar energy is the ultimate source of energy where different species in the biotic community compete for various resources (e.g. nutrients, water, etc.) due to their limited amount. This would lead to have a controlling mechanism either top-down or bottom-up to keep the balance of the biotic communities in the terrestrial ecosystems. For example, herbivores depress plants; predators depress herbivores; predators thus indirectly facilitate plants through their cascading effects. $6,10,11,25-27,30,31$ Despite the presence of variety of evidence accumulated to suggest a strong role of consumers' effects and trophic cascades in the terrestrial ecosystems, most of them argue to represent species level trophic cascades. ${ }^{26,30,31}$ Decomposers do not have a trophic level above. It does not seem that climate can control them. So, it is most likely that they are controlled by the trophic level below them (i.e., litters). ${ }^{5,6,17,30,31}$ Theoretical models also suggested that both resources and predators interact to structure the natural food webs and thereby reduce the impacts of herbivory on green plants in the terrestrial ecosystems. ${ }^{5,6}$ For example, the HSS model predicted that strong competition is observed in trophic levels of producers, predators, and decomposers. However, no competition was predicted between herbivores. Does the model give valuable predictions? In general yes, competition is a very strong force, but the details are not clearly addressed in the HSS model. This is because in a closed system, herbivores are observed to deplete their own foods and start to compete among themselves for limited plant resources. ${ }^{6}$ However, this rarely occurs in open natural systems where herbivore populations' size is checked by their natural predators. ${ }^{5,6,7,16}$ Understanding the mechanisms by which natural populations are limited in size in the terrestrial communities have been the core point of debate in ecological studies and usually confined to single species. For example, the vagaries of weather have been suggested as adequate mechanism of control for herbivore populations in the terrestrial ecosystems. ${ }^{27}$ However, others suggested that predation is the mechanism of herbivore control in natural system. In fact, extant 
terrestrial herbivores usually consume a small fraction of net annual primary productivity (about 5-10\%) especially in the forest ecosystem compared with the huge biomass produced by green plants in the terrestrial ecosystems, ${ }^{29}$ Figure 5. Polis ${ }^{12}$ also noted that on average less than one fifth of the net annual primary productivity is consumed by herbivores; however, the rest remaining as standing biomass or becoming detritus.

Despite the fact that grazing plays comparatively minor role for land plants on a global scale, herbivory is still quite important at finer scales. In some communities, herbivores consume large portion of the net annual primary productivity and transfer plant biomass into a large standing biomass of animals. For example, in the grassland ecosystem, herbivores are larger in their body size compared to the desert or the forest ecosystems. Body size may give advantage for large herbivores to utilize the crude grasses and other low quality plant food materials until occasional food depletion is observed in grassland ecosystem, but it is unstable equilibrium. ${ }^{4}$ Nevertheless, such heavily grazed systems with high secondary productivity maintain substantial standing biomass (e.g. African savannah). Of course, the ultimate effect of overgrazing in the system may bring changes in species composition of plants as palatable species would be replaced by the non-palatable ones. ${ }^{32-34}$ Overgrazing of the natural vegetation by herbivores could leave little standing plant biomass; however, this is a rare phenomenon in the natural system because it occurs, for example, when there is out breaks of insect herbivores and introduced voracious grazers into a closed system by man. ${ }^{12,35,36}$ In fact, introduced exotic grazers often change the structure and species composition of plant communities by selectively removing certain palatable plant species while leaving the unpalatable ones. Thus, terrestrial herbivores have the ability to reduce standing plant biomass and thus greenness at least in some places and times where unstable equilibrium is maintained. ${ }^{4}$

Intrinsic characteristics of key consumers and resources could affect the cascading effects of predators in the given systems. ${ }^{12}$ However, the life of the plant may matter to be affected by consumers because only some plant species and life stages can be regulated effectively by consumption depending on the level of palatability, chemical, and structural defenses and toxicity, nutrient content, duration of vulnerable stages and reproductive capacity to dominate the system. ${ }^{3,26}$ Green plants also replenish their damaged and removed parts by herbivores though it is energetically a costly process. However, consumers that exert strong cascading effects within a particular plant-herbivore food chain are almost always deeply subsidized by resources from many sources outside the focal chain., ${ }^{3,12}$ Let us see how trophic cascade and population control works in the following three types of terrestrial ecosystems.

\section{Communities in the tropical rain forest ecosystem}

Because of its optimal temperature and rainfalls, the tropical rain forest ecosystem seems to be the most productive ecosystem on the planet earth. ${ }^{37}$ It is highly diversified in its biotic communities' composition and complexity as well as food web interactions. Most of the browsing mammals in this ecosystem are small in their body size see Figure 6 . This is because large body sized herbivores cannot reach the top of big tree crowns where fresh and palatable leaves are available. However, insect herbivores are more diversified and abundant in this ecosystem. Moreover, frugivore and nectar feeding birds are commonly observed. Most of the primary production (90$95 \%$ ) goes to the decomposers because there is very low consumption efficiency by herbivores. ${ }^{22,29}$ Plants also have developed different defensive mechanisms to reduce the impact of browsing herbivores. For example, plants use secondary metabolites to defend themselves from excessive browsing by herbivores. ${ }^{38}$ Moreover, the predators, which rely on insect herbivores and other small browsers, are arthropods, birds, small predatory mammals, reptiles, and amphibians. ${ }^{17}$

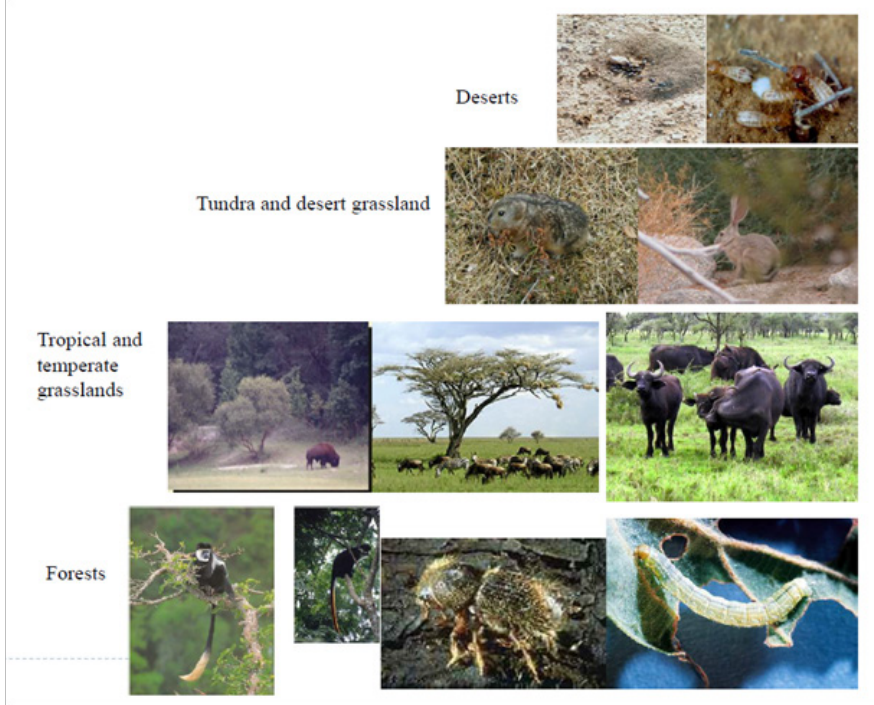

Figure 6 Schematic representation showing the changes in herbivore body size with productivity.

All these high diversities of species at various trophic levels make the control of biotic communities' complex in the tropical rain forest ecosystem. Thus, they lack clear trophic levels especially among predators. They are potential for high inter-trophic level interactions both along (e.g. prey-predator) ${ }^{13,23,24}$ and across (e.g. competition among guild species $)^{17-22}$ food webs. Therefore, herbivores population control and the cascading effect of predators on plants seem to be a bit complex and messy to explain both in temporal and spatial frames compared with the shaping and controlling mechanisms of biotic communities in the grassland or the desert ecosystem. Moreover, there are different species of omnivorous organisms in this biotic community that make assigning them to a specific trophic level difficult. For example, Morris ${ }^{39}$ noted that omnivores have not figured prominently in our understanding of food webs though they can have substantial direct and indirect effects on the structure of the terrestrial communities, and also on the abundance, distribution, and dynamics of interacting species in the system.

\section{Communities in the grassland ecosystem}

Grasslands are associated with human activity and their origin and maintenance were mostly linked with forest clearing and subsequent management, such as mowing, grazing by domestic livestock, and even recurrent fire. ${ }^{37}$ Grasses are annuals so that decomposers play a great role in recycling of dead plants and releasing of organic matters which in turn facilitate the growth of palatable and fresh grasses for herbivores. As a result, grassland ecosystem supports large number of herbivores whose population is largely checked and regulated by predators. ${ }^{3}$ However, the food chains are shorter and food webs are less complex compared to the tropical rain forest ecosystem. ${ }^{13,17}$

In grassland ecosystem, the grazing herbivores are mostly large in their body size see Figure 6 so that they can only be controlled by big body sized predators or by those predators which engage in 
group hunting. However, one advantage for a grazer to be big in body size is the ability to locate predators from a distance and run fast to save its life. Moreover, big body sized grazers such as African buffalo Syncerus caffer defend themselves from predators' attack while they are grazing in big groups. When the grassland is surrounded by human settlements and when there is a problem of an outlet for migration corridors, grazers are sometimes observed to deplete the plant resources and become susceptible to starvation. ${ }^{69}$ Grassland ecosystem is more productive compared to what the desert ecosystem is see Figure $3 \& 7$. Thus, the cascading effect of top predators on plant communities in the grassland ecosystem is strong..$^{26}$ Moreover, both biotic and abiotic factors work together to shape and control the size and the structure of the grassland communities. . $^{13,17,25}$

\section{Communities in the desert ecosystem}

Desert ecosystem is biologically less productive, for example, due to the scarcity of water as a limiting resource. ${ }^{40}$ Ayal et al. ${ }^{41}$ also noted that the low diversity of organisms in desert ecosystem is the harsh environmental conditions which limit the number of organisms that are able to survive in this environment. Desert communities are believed to be resource-controlled since the amount of precipitation determines the level of primary productivity. ${ }^{42}$ This is because low primary productivity limits the amount of energy available to higher trophic levels and can be a likely mechanism that may limit the number of organisms in deserts. It was suggested that predators do not play an important role in the determination of the abundances and distributions of animal populations in desert habitats ${ }^{14,15,42}$ though some field studies have demonstrated that desert predators have a role to play in determining the abundance and habitat segregation of their prey. ${ }^{19,43-49}$ A positive correlation between productivity level and the number of organisms at higher trophic levels has been suggested for a long time. ${ }^{22,29}$ For example, some empirical ${ }^{20,50}$ and theoretical ${ }^{6}$ studies that supported the low primary productivity reduces the number of animals at higher trophic levels in the desert ecosystem. This alone reduces diversity and also diminishes the intensity of biotic interactions within the desert terrestrial communities..$^{14,15,42}$ This suggests that biotic interactions are important in maintaining high diversity in natural communities. As a result, communities in desert ecosystem are less diversified with less complex biotic communities compared to other terrestrial ecosystems ${ }^{6,13,16,25}$ see Figure 3. For example, plant communities are mostly confided in valleys and wadis where the soil is deep and fertile as well as ground water is near to the soil surface. ${ }^{13,27,51}$

In desert ecosystem, herbivores and their associated predators are mostly small in their body size. For example, many herbivores are small mammals, birds, insects, and other small arthropods. ${ }^{13,17,27,50}$ Moreover, biotic communities are less complex. And food webs are mostly less complex relatively in the form of long food chains. For example, Menge and Sutherland ${ }^{8}$ noted that food web complexity decreases with increasing environmental stress. Most of the trophic levels in the desert ecosystem are based on the litters and detritivores. For example, Ayal ${ }^{13}$ noted that due to the scarcity of water resource in the desert ecosystem, micro detritivores mostly live as symbiotic inside the digestive systems of other macro-detritivores and facilitate digestion of hard dead plant materials for common benefits. However, there is a high diversity of predators and primary consumers in the desert ecosystem ${ }^{27}$ see also Figure 4. Ayal ${ }^{13}$ also suggested that predators are not efficient either because productivity is too low to support a predator trophic level or sufficiently high to allow predators of predators to limit them. As a result, compared to both the tropical rain forest and the grassland ecosystems, the influence of abiotic factors in controlling and shaping the structure and size of biological communities is the strongest in the desert ecosystem due to the energy limitation hypothesis. ${ }^{6,14,15,16}$ The Fretwell-Oksanen model also predicts an increase in the number of trophic levels with the increase in productivity gradient (i.e., the ELH) Figure 7. However, in a recent theoretical study, it was hypothesized that the combination of productivity and organism size is crucial to determine the potential of the number of trophic levels in the terrestrial ecosystems. ${ }^{17}$ Unlike previous arguments made on the number of tropic levels in the desert ecosystem i.e., due to the ELH; e.g., ${ }^{6,14-16,51}$ Ayal ${ }^{17}$ argued that in the desert ecosystem, the potential number of trophic levels can reach up to five links, suggesting that vertical and horizontal interactions should be combined to determine the distribution of biomass in terrestrial ecosystem see Figure 8. This implies that future empirical studies are crucial to test the recent hypothesis proposed by Ayal. ${ }^{17}$

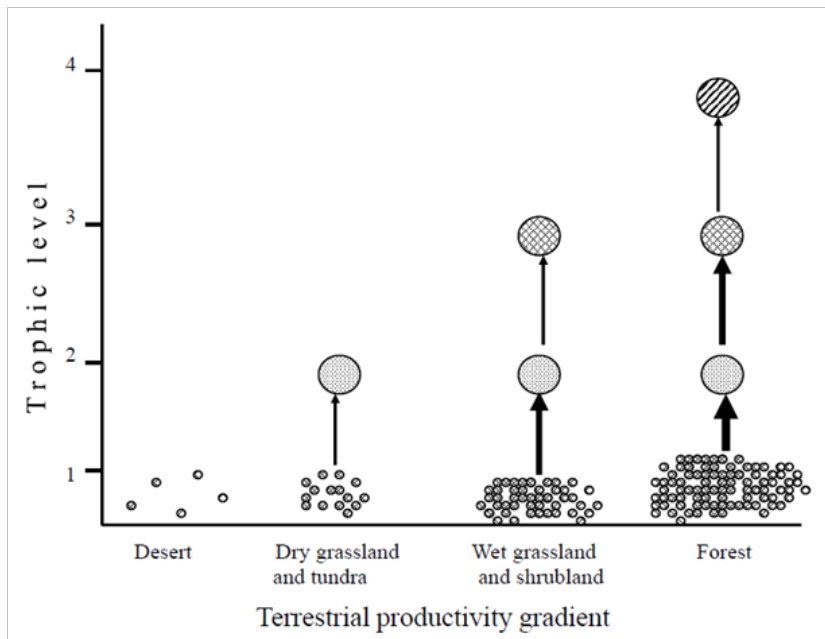

Figure 7 The Fretwell-Oksanen prediction on the increase in the number of trophic levels with productivity due to the energy limitation hypothesis. (Adapted from ${ }^{6}$ based on the model predicting the ecosystem exploitation hypothesis).

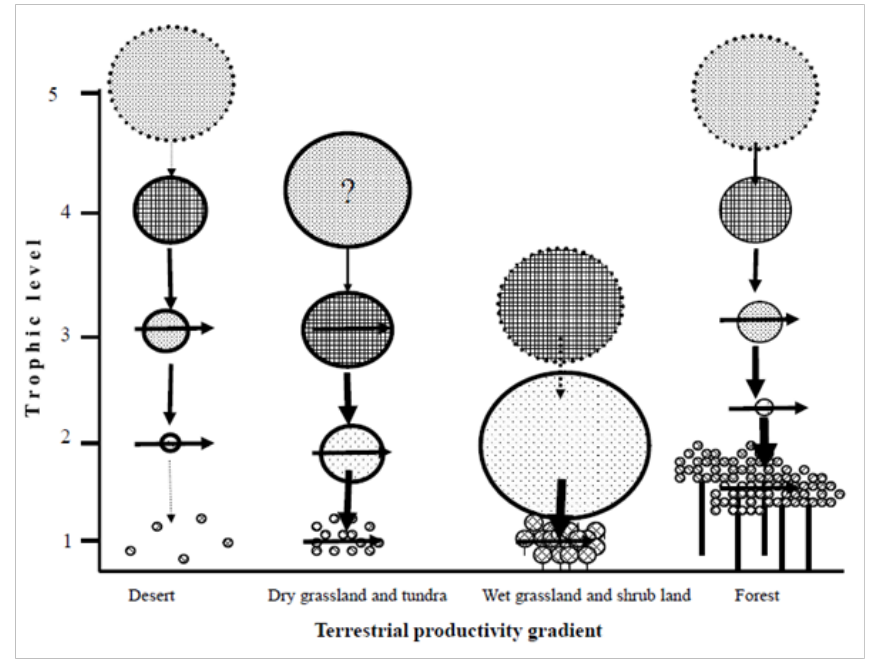

Figure 8 The structure of terrestrial biomes according to the hypothesis suggested by Ayal. ${ }^{17}$ Small circles at the first trophic level (primary producers) represent edible parts of the plants; vertical line represents inedible ones. Ayal ${ }^{17}$ predicts the increase in animal size with trophic position (i.e., represented by circle sizes) and potentially up to five trophic levels. Dashed circle circumference suggests a potential trophic level that is excluded either by energy (e.g. deserts), size limitation (e.g. grasslands), or as a result of plant physiognomy (e.g. forests). 


\section{Conclusion}

Community is one of the hierarchies of ecological organizations containing different species of organisms interacting in space and time. The structural components of the biotic communities are mainly composed of plants, animals, and microbes. Compared to the aquatic ecosystems, the terrestrial biotic communities are functionally more diversified and complex. This is because the number of trophic levels increases with the increase in productivity gradients. Herbivores closely interact and depend on green plants in order to acquire their ecological requirements (e.g. food and energy). However, herbivores are in between the devil (i.e., predators) and the deep blue sea (i.e., most portions of green plants are crude and inedible to herbivores) which may lead herbivores to high energetic costs of foraging and predation risks. Moreover, green plants have evolved various defensive mechanisms to reduce the negative impacts of herbivores that otherwise result from grazing and browsing. So, different factors may interact together and synergistically affect the structure of the biotic communities in the terrestrial ecosystems. For example, primary productivity of a system is markedly affected by precipitation, incident light, temperature, disturbance, nutrients, and resistance to herbivory and cascading food web effects. Thus, holistic approach should be sought for any conceptual models to explain patterns of productivity and biomass distribution in the terrestrial communities. This in turn would help to effectively simulate community structure, trophic level interactions, and control of the terrestrial biotic communities with reference to specific spatial and temporal scale. Moreover, the role of behavior and life history traits, prey defenses versus prey tolerance are important factors which could affect the structure, complexity, and diversity of food webs in the terrestrial biotic communities. In conclusion, the different hypotheses developed by various scholars of the community ecology have to be considered in an integrated fashion in order to clearly understand and explain the plausible mechanisms that influence community structure and trophic level interactions in the terrestrial ecosystems.

\section{Acknowledgements}

SAT designed the study and wrote the manuscript.

\section{Conflict of interest}

The author declares no conflict of interest.

\section{References}

1. Coley PD, Bryant JP, Chapin FS. Resource availability and plant antiherbivore defense. Science. 1985;230(4728):895-899.

2. Hartley SE, Jones TH. Plant diversity and insect herbivores: effects of environmental change in contrasting model systems. Oikos. 2003;101(1):6-18

3. Hartley SE, Jones TH. Insect herbivores, nutrient cycling and plant productivity: a review. Insects and ecosystem function. In: WW Weisser, E Siemann, editors. Ecological Studies. 2004. 137:27-52.

4. MacFadden BJ. Cenozoic mammalian herbivores from the Americas: reconstructing ancient diets and terrestrial communities. Annual Review of Ecological Systematics. 2000;31(2000):33-59.

5. Hairston HG, Smith FE, Slobodkin LB. Community structure, population control, and competition. American Naturalist. 1960;94(879):421-425.

6. Oksanen L, Fretwell S, Arruda J, et al. Exploitation ecosystems in gradients of primary productivity. The American Naturalist. 1981;118(2):240-261.
7. Oksanen J. Reindeer lichen (Cladina) vegetation of rock outcrops on a coast-inland transect in South Finland. Annales Botanici Fennici. $1981 ; 18(2): 133-154$

8. Menge BA, Sutherland JP. Community regulation: variation in disturbance, and predation in relation to environmental stress and recruitment. American Naturalist. 1987;130(5):730-757.

9. Creel S, Winnie J, Maxwell B, et al. Elk alter habitat selection as an antipredator response to wolves. Ecology. 2005;86:3387-3397.

10. Ripple WJ, Beschta RL. Wolf reintroduction, predation risk and cottonwood recovery in Yellowstone National Park. For Ecol Manage. 2003;184:299-313.

11. Ripple WJ, Beschta RL. Wolves and the ecology of fear: Can predation risk structure ecosystems. Bio Science. 2004;54(8):755-766.

12. Polis GA. Why are parts of the world green? Multiple factors control productivity and distribution of biomass. Oikos. 1999;86(1):3-15.

13. Ayal Y. Arthropod communities in deserts are top-down controlled: an example from the Central Negev, Israel. Israel Journal of Zoology. 1998;44:68-92.

14. Noy Meir I. Desert Ecosystems: Environment and Producers. Annual Review of Ecology \& Systematics. 1974;5(25):1-19.

15. Noy Meir I. Desert ecosystem structure and function. In: Evenari M, Noy meir, editors. Hot deserts and arid shrub lands. Netherlands; 1985. p. 93-103.

16. Oksanen L. Predation, herbivory, and plant strategies along gradients of primary productivity. In: Tilman D, Grace J, editors. USA: Academic Press; 1990. p. 445-474.

17. Ayal Y. Productivity, organism size, and the trophic structure of the major terrestrial biomes. Theor Ecol. 2010;4(1):1-11.

18. Schoener TW. Resource partitioning. Community ecology: pattern and process. In: Kikkawa J, Anderson DJ, editors. USA: Blackwell Scientific Publications, Oxford; 1986

19. Abramsky Z, Shachak M, Subach A, et al. Predator-prey relationshipsrodent-snail interactions in the Central Negev Desert of Israel. Oikos. 1992;65(1):128-133.

20. Rosenzweig ML. Optimal habitat selection in two-species competitive systems. Fortschritte der Zoologie. 1979;25:283-293.

21. Rosenzweig ML. A theory of habitat selection. Ecology. 1981;62(2):327335.

22. Elton C. Animal ecology. The animal community. 1927:1-15.

23. Rosenzweig ML, MacArthur RH. Graphical representation and stability conditions of predator-prey interaction. American Naturalist. 1963;97(895):209-223

24. Kotler BK, Blaustein L. Titrating food and safety in a heterogeneous environment: when are the risky and safe patches of equal value. Oikos. 1995;74(2):251-258.

25. Feeny P. Seasonal changes in oak leaf tannins and nutrients as a cause of spring feeding by winter moth caterpillars. Ecology. 1970;51(4):565581

26. Chase JM. Strong and weak trophic cascades along a productivity gradient. Oikos. 2003;101(1):187-195.

27. Ayal Y. Trophic structure and the role of predation in shaping hot desert communities: a review. Journal of Arid Environments. 2007;68:171-187.

28. Makkar HPS, Blummel M, Becker K. Formation of complexes between polyvinyl pyrrolidones or polyethylene glycols and tannins, and their implications in gas production and true digestibility in invitro techniques. Br J Nutr. 1995;73(6):897-913. 
29. Lindeman R. The trophic-dynamics aspects of ecology. Ecology. 1942;23(4):399-418.

30. Estes JA, Duggin DO. Sea otters and kelp forests in Alaska-generality and variation in a community ecological paradigm. Ecological Monographs. 1995;65(1):75-100.

31. Murdoch WW. Community structure, population control, and competition. A critique. American Naturalist. 1966;100(912):219-226.

32. Kebede AT. Sustaining the Allideghi grassland of Ethiopia: influence of pastoralism and vegetation change. USA: Utah State University; 2009. $309 \mathrm{p}$.

33. Tadesse SA, Kotler BP. The impacts of humans and livestock encroachments on the habitats of mountain nyala (Tragelaphus buxtoni) in Munessa, Ethiopia. International Journal of Biodiversity and Conservation. 2013;5(9):572-583.

34. Wassie A, Sterck FJ, Teketay D, et al. Effects of livestock exclusion on tree regeneration in church forests of Ethiopia. Forest Ecol Manage. 2009;257:765-772.

35. Silori CS, Mishra BK. Assessment of livestock grazing pressures in and around the elephant corridors in Mudumalai Wildlife Sanctuary, South India. Biodiversity \& Conservation. 2001;10(12):2181-2195.

36. Smit C, Ouden JD, Mueller-Schaerer H. Unpalatable plants facilitate tree sapling survival in wooded pastures. J Appl Ecol. 2006;43(2):305-312.

37. Bredenkamp GJ, Spada F, Kazmierczak E. On the origin of northern and southern hemisphere grasslands. Plant Ecology. 2002;163(2):209-229.

38. Butler LG, Roger JC. Biochemical mechanics of the anti-nutritional effects of tannins. ACS Symposium Series. 1992;506:298-304.

39. Morris D. Paradoxical avoidance of enriched habitats: have we failed to appreciate omnivores. Ecological Society of America. 2005;86:25682577.

40. Ehleringer JR. Productivity of deserts, Terrestrial Global Productivity In: Roy J, Saugier, et al. editors. England: Academic Press; 2001. p. $345-362$.
41. Ayal Y, Gary A, Polis AG, et al. Habitat productivity and arthropod community structure in deserts: the productivity-structure hypothesis. Israel: Abstracts of presentations at the public conference at Zonenfeld Hall, Ben-Gurion University New Campus; 1999.

42. Noy Meir I. Desert ecosystems: environment and producers. Annual Review of Ecology and Systematics. 1973;4:25-41.

43. Ayal Y, Merkl O. Spatial and temporal distribution of tenebrionid species (Coleoptera) in the Negev Highlands, Israel. Journal of Arid Environments. 1994;27:347-361.

44. Brown JH, Heske E. Control of a desert-grassland transition by a keystone rodent guild. Science. 1990;250(4988):1705-1707.

45. Brown JH, Davidson DW, Munger JC, et al. Granivory in A Desert Ecosystem: Experimental Evidence for Indirect Facilitation of Ants by Rodents. Community Ecology. 1984;65(6):1780-1786.

46. Groner E, Ayal Y. The interaction between bird predation and plant cover in determining habitat occupancy of darkling beetles. Oikos. 2001;93(1):22-31.

47. Polis GA, Barnes JD, Seely MK, et al. Predation as a major cost of reproduction in Namib Desert tenebrionid beetles. Ecology. 1998;79(7):2560-2566.

48. Shachak M, Safriel UN, Hunum R. An exceptional event of predation on desert snails by migratory thrushes in the Negev Desert, Israel. Ecology. 1981;62(6):1441-1449.

49. Yom Tov Y. The effect of predation on population densities of some desert snails. Ecology. 1970;51(5):907-911.

50. Wright DH. Species-energy theory: an extension of species-area theory. Oikos. 1983;41(3):496-506.

51. Tadesse SA. Determinants of habitat selection and patch use behavior of nubian ibex (Capra nubiana) in Israel. MSc Thesis. Israel: Ben-Gurion University of the Negev; 2008. 126 p. 